decreased and by the eighth the diarrhœa had altogether ceased.

The experience of many other continental physicians coincides with that of Dr. Landau; indeed, he quotes them frequently in support of his own statements as to the value of somatose, and there can be no doubt that this preparation has been administered in sufficient quantities to produce highly beneficial results. May we not, therefore, be justified in assuming that in those cases in which the results have been unsatisfactory the method of administration of somatose has had more to do with the production of diarrhoea than has the preparation itself, seeing that when certain precautions are taken diarrhcea is mostly absent and that its use has been attended with marked success in the hands of very many physicians?

I am, Sirs, yours faithfully,

T. POYNTZ WRIGHT,

St. Neots, Hunts, August 18th. Medical Officer of Health.

\section{THE SIMULATION OF ABDOMINAL DISEASE BY INTRA-THORACIC LESIONS.}

To the Editors of THE LANCET.

SiRS, - In a leading article in THE LANCET of August 16th you refer to papers bearing on the above subject by $\mathbf{M r}$. H. L. Barnard ${ }^{\mathcal{1}}$ and by Dr. Jane $H$. Walker in the Mirror of Hospital Practice, ${ }^{2}$ and you well emphasise the necessity of being on one's guard and making examination of the thoracic region, especially in the case of surgeons. Now, in most of these cases, if not in all, careful examination of the chest will, even at the earliest period, throw light on the problem. Mr. Barnard candidly admits that error in the diagnosis is asually due to neglect on the surgeon's part to have the chest examined -_" the diagnosis is nearly always easy, if suspicion is aroused and the surgeon is aware of this deceptive condition." With regard to the case reported by Dr. Jane Walker, it is, to say the least, unsatisfactory. It is stated that at a period when the respiration varied from 18 to 54 per minute and the pulse-rate from 90 to 128 "her chest, which was carefully examined every day, showed no abnormal signs." Now, Sirs, it would be interesting to know exactly in what the examination of the chest consisted. For my part, I cannot believe that diaphragmatic or other obscure basal pleurisy could possibly exist without a marked diminution, if not abolition, of the shadow movement (Litten's) on the corresponding side. On the other hand, if the lesion was really under the diaphragm the shadow might remain unaffected. The abolition or restriction of the shadow movement would be quite compatible with negative signs on auscultation and percussion. There is another expression in the narration of this case which deserves notice-viz. : "Some muco-purulent material being expectorated which was examined for both tubercle bacilli and other organisms with a negative result." What is meant by "other organisms"? Are we to believe that the sputum in this particular case was sterile? Was the sputum injected into animals?

May I end by saying that it would be well if in narrating important cases authors would state the precise details of their methods of examination. It is easy to conceive that the omission of a single diagnostic test might convert a comparatively plain situation into one of grave difficulty.

I am, Sirs, yours faithfully,

Henrietta-street, W., August 18th, 1902.

A. G. AULD.

THE ETHICAL SECTION AT THE RECEN'T MEETING OF THE BRITISH MEDICAL ASSOCIATION.

To the Editors of THE LANCET.

SIRs, - While reporting the transactions in the Section of Ethics (annual meeting British Medical Association) as stated in THE LANCET of August 9th, p. 390, your representative, as a rule extremely accurate and impartial, has on this occasion, unwittingly I am certain, fallen into two errors relative to myself. The first, a very minor slip on p. 390, second column, third line from the top: "more than $£ 1000$ " should read "nearly £1000." The second, rather more important, p. 391, is contained in the concluding

1 The Lancet, August 2nd, 1902, p. 280. paragraph, "The motion was carried with one dissentient vote, given by Dr. W. Muir Smith of Eastbourne." As a matter of fact, I did not vote either way ; at least, I have no recollection of voting in favour of, and am absolutely certain I did not vote against, the resolution. Certainly there was one dissentient, and the confounding myself with another may be explained by the fact that the voter in question was seated next to me. I am, Sirs, yours faithfully,

Eastbourne, August 13th, 1902.

WM. MUIR SMITH.

\section{WALES AND WESTERN COUNTIES NOTES. (FroM OUR OWN CORRESPONDENTS )}

\section{Memorial Tablet to the Staff of the Welsh Hospital.}

THERE was unveiled on August 14th in St. David's Cathedral, by Lord Penrhyn, a memorial tablet recording the names of the members of the medical and nursing staff of the Welsh Hospital who died during the war in South Africa. The inscription on the tablet was :-

THE WELSH HOSPTAL

IN SouTH AFRICA.
This Tablet was placed in this Cathedral Church by the

Committee of the Welsh Hospital

in South Africa in Memory of

in South Africa in Memory of
those members of the medical and

nursing staff of the hospital

who died for their country 1900 and 1901.

Professor Alfred William Hughes, M.B., F.R.C.S.

Professor Thomas JoNes, M B., F.R.C.S HERBERT DAVIES, M.B.

THOMAS RICHARD EAMES, dresser.

MaRion Lloyd, Royal Red Cross Matron.

Florence Louise Sage, nursing sister. Gorphwysant.

The graceful eulogy of Lord Penrhyn when he handed over the memorial to the care of the Dean and Chapter and the impressive tribute of Dean Howell in accepting the charge will long be remembered by those who took part in the cathedral service. In the course of his address the Dean said that not less brave or less chivalrous than those who were stricken down by disease or the sword were those who day by day and night after night stood face to face with death within the Welsh Hospital, for with them was not the rush and excitement of the battlefield, nor the wild impulse of the fray, nor the over. mastering passion for victory, but only the calm consciousness that they were doing their duty to their country and countrymen. It will be remembered that the Welsh Hospital was established in the spring of 1900 and that Professor Alfred Hughes, after acting as organising secretary in this country, went out to South Africa as chief surgeon upon the death of Professor Thomas Jones. The hospital was first of all located at Bloemfontein, afterwards at Springfontein, and was finally converted into an officers' hospital at Pretoria. A total sum of about $£ 12,000$ was subscribed in support of the undertaking and of this $£ 8000$ were expended. Of the balance $£ 1200$ have been given to hospitals in Wales and the remaining $£ 2800$ are to be distributed among incapacitated Welsh soldiers and the widows and orphans of those who died during the war.

During the week ending August 16th one case of small. pox occurred at Caerphilly and terminated fatally. There is no means of isolating cases of infectious disease in this district, but an iron hospital has been hastily erected. There were three cases of the disease reported in Neath, two of the patients being officers of the workhouse. The epidemic appears practically to have subsided in Swansea, one case only having been reported during the period named, while in the previous week there were eight cases. The vaccination stations in Swansea were closed on August 14th.

Maintenance of Lunatics in Workhouses.

The Bristol board of guardians has decided to ask the Local Government Board to promote legislation for the purpose of securing to boards of guardians a grant of $3 s$. per week towards the maintenance of lunatics, imbeciles, and epileptics who are not sent to lunatic asylums or licensed houses but who are kept in workhouses or in special institutions connected with workhouses. At present boards of guardians receive from the exchequer grants of the county council $4 s$. per week towards the maintenance of each 